\title{
Re-engineering of thought process: An exploratory model.
}

\author{
Santa Misra* \\ SSS College for Women, Bhubaneswar, Odisha, India
}

\begin{abstract}
From the Vedic and pre-Vedic period, even the time immemorial, thought process regulation is being highlighted and implemented by the Saints and Rishies for the wellbeing of the people. This 'the-then' ongoing process has now reached in the step of Thought Process Re-engineering (TPR), which is just an avenue to recycle the concept of regulating one's own thought Process. The very concept of TPR is emerged combining the Science and Spirituality with a base of quantum physics, in re-processing of thought process, focused by Sajeev Nair. According to him the process of re-engineering of thought is being worked out in seven stages like:- Be Conscious- Pause Replay- Ask- Explore- Retrieve and then Play. The present article, based on this idea, aims at exploring and preparing a model in re-engineering of thought on the basis of neuroscientific exploration adhered with higher level of mental functioning in circulating, regulating and managing the mindset we have, in a particular manner to remove the affliction and negative thoughts from the cognitive and conative level helping the person to live in a healthy mind with a healthy body. The process can be designed as: - Be conscious $\Rightarrow>$ then Focus (attention) $\Rightarrow>$ Explore (Neuro- scientifically) $\Rightarrow$ Pause (To judge) $\Rightarrow$ Retrieve $=>$ Reasoning $\Rightarrow$ Reframe $=>$ Action/Play $=>$ Behaviour. In this process if we will be conscious about our good action and it will be circulated through TPR technique then we will have a healthy body with a healthy mind. For example, if we have good thought, it leads good action- that leads to good character - then lead to good behavior - then good display- by which we can have a good life. And in a circular manner it revolves But if we have a bad thought, it leads to all bad mentality- bad action- bad characterbad behavior- bad display ultimately leads to bad life and when repeating it again and again we will get only bad and bad results (Sajeev Nair). In this age of technology where everything is technologically induced, like biotechnology, information technology, media technology, peace technology, etc., our thought process also can be re-engineered technologically, upon which an exploratory model is reflected in this paper. The model implicates in answering to the questions like: what one believes to be true/good, how to differentiate between good and bad (as they are relative terms), how confident one is in that belief, about how we answer to a question in terms of the inferential processes whereby knowledge is constructed from perceptions and memories, and above all how the thought process of the people can be changed so as to create a desired result of meaningful and holistic life.
\end{abstract}

Keywords: Thought process re-engineering, Neuro-scientific exploration, Affliction, Neuro-exploratory model.

Accepted on March 24, 2017

\section{Introduction}

This paper is based on the uniqueness of Thought Process Re Engineering (TPR) which is built up with the combination of Neuro-science, spirituality and quantum physics. The very concept of TPR, Pioneered by Sajeeev Nair, aims at making somebody conscious about their own thoughts [1].

What we are and what we will be in our life is the outcomes of our thought process depending upon our cognitive capacity. This thinking and imagination creates curiosity and the curiosity leads us to be exploratory, Only for this exploration of thought process the primitive man can able to reach now in the adventure of $21^{\text {st }}$ century. The thought process regulation is based on principles of Neuroscience, Quantum physics and spirituality.
Neuroscience is the scientific study of the nervous system (Merriam-Webster Medical Dictionary) and currently as an interdisciplinary study collaborates with different disciplines, from which focus is given here on Cognitive and behavioral neuroscience. The cognitive neuroscience describes how psychological functions are the result of neural circuitry; how human cognition and emotion are mapped to specific neural substrates; and how interesting interplay occurs between neuroscientific findings and conceptual research, which solicits and integrates both the perspectives of human life that regulates the thought processes and the decision making process.

Quantumphysicsisa fundamentalbranch of physics concerned with processes involving, nature and behavior of matter and energy in atoms and photons. The TPR deals with this 
principle of quantum physics starting the function of the thought process from the grass root level in its cyclic order and helps in building the behaviour and character.

Spirituality is the knowledge concerning to the management of human life relating to the physical and metaphysical world to determine the existence and identity of one's own self. Spirituality refers to the "deepest values and meanings by which people live“. It embraces the idea of an ultimate or an alleged immaterial reality. It envisions an inner path enabling a person to discover the essence of his/her being. It aims atmerge of 'PETTY SELF' with 'UNIVERSAL SELF'.

According to Kotsos thought power is the key to creating the reality. Everything one perceives in the physical world has its origin in the invisible inner world of the thoughts and beliefs. To become the master of that destiny, one must learn to control the nature of one's dominant and habitual thoughts. By doing so, one can able to attract into the reality of life that one intend to have and experience (Figure 1).

Each and every behaviour is attracted by an inner cause. This inner thought image is always alive and limitless. The basic principle is as energy attracts energy we are being attracted to those things and circumstances that are in vibrational harmony with our dominant frequency, which is itself determined by our dominant mental processing, i.e., attitude, habitual thoughts and beliefs. Mike Dooley, one of the presenters of the movie The Secret, suggests that 'if we want to know what a thought looks like, just look around you. Keep in mind these three words "thoughts are things"'. Similarly Siddhartha Gautama Buddha, perfectly captured the essence of thought power, i.e., "All that we are is the result of what we have thought. The mind is everything. What we think we become" (Figure 2) [2].

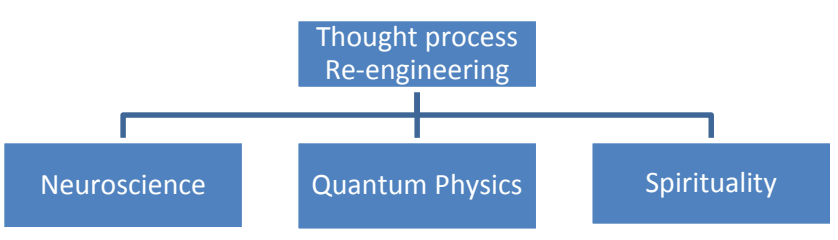

Figure 1. Showing the base of TPR.

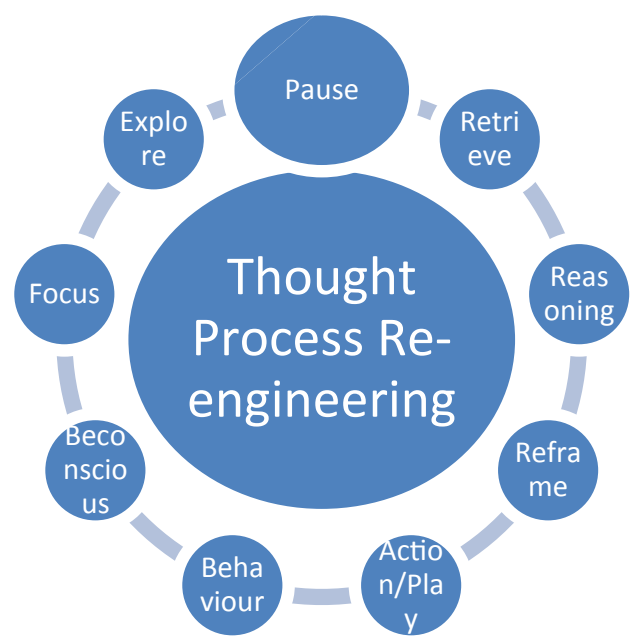

Figure 2. This picture is a representation of how TPR functions.
TPR - Be conscious $=>$ then Focus (attention) $=>$ Explore (Neuro- scientifically) $=>$ Pause (To judge) $\Rightarrow$ Retrieve $=>$ Reasoning $=>$ Reframe $=>$ Action $/$ Play $=>$ Behaviour - TPR

According to Sajeev Nair, the process of re-engineering of thought is being worked out in seven stages like:- Be Conscious- Pause - Replay- Ask- Explore- Retrieve and then Play. The present article, based on this idea, aims at exploring and preparing a model in re-engineering of thought on the basis of neuroscientific exploration adhered with higher level of mental functioning in circulating, regulating and managing the mindset we have, in a particular manner to remove the affliction and negative thoughts from the cognitive and conative level helping the person to live in a healthy mind with a healthy body. The process can be designed as:- $\mathrm{Be}$ conscious $=>$ then Focus (attention) $\Rightarrow$ Explore (Neuro- scientifically) $\Rightarrow>$ Pause ( To judge) $\Rightarrow$ Retrieve $=>$ Reasoning $=>$ Reframe $=>$ Action/Play $\Rightarrow$ Behaviour. In this process if we will be conscious about our good action and it will be circulated through TPR technique then we will have a healthy body with a healthy mind. For example, if we have good thought, it leads good action- that leads to good habit, when there is the continuation of habit it leads to character - then this character in conditioning process lead to good behaviour - this good display can be resulted to a good life. And in a circular manner it revolves But if we have a bad thought, it leads to all bad mentality- bad actionbad character- bad behaviour- bad display ultimately leads to bad life and when repeating it again and again we will get only bad and bad results (Sajeev Nair). In this age of technology where everything is technologically induced, like biotechnology, information technology, media technology, peace technology, etc., our thought process also can be reengineered technologically, upon which an exploratory model is reflected in this paper. The model implicates in answering to the questions like: what one believes to be true/ good, how to differentiate between good and bad (as they are relative terms), how confident one is in that belief, about how we answer to a question in terms of the inferential processes whereby knowledge is constructed from perceptions and memories, and above all how the thought process of the people can be changed so as to create a desired result of meaningful and holistic life.

Sajeev Nair founded the most powerful Neural Level ReProgramming, called Thought Process Re-engineering (TPR) after doing a thorough research for more than 6 years. TPR is helping thousands of people to come out of phobias, to have high level of confidence and self-image, to break all the mental barriers and to truly manifest one's dream life. He has converged some of the NLP techniques also to include in TPR.

The power of thought is incredible. We have to be aware of our own thoughts - they are powerful cosmic waves in universal sea of energy we live in. The mental wave lengths we all have include the total social and cultural wellbeing. If a person having good display and good thoughts for others even good thought for those who treat him/her as enemy, it 
will expand to all, through this mental wave length. Thus our thought creates our own world. By changing our own thought we can also change our world around us. In order to change the way we think, literally we need to re-engineer our brain at the neuro level. Thought Process Re-engineering (TPR) is a unique program, which helps to re-engineer the neural wirings. It helps to create new neural pathways in our brain, which can have a permanent and lasting effect on our thoughts.

The fact is our brain generates thoughts based on the inputs. . It has been receiving through the senses. These senses are outcome of the 'Pancha Mahavuta' as a living being of this beautiful earth. All the five senses we get, we get them from this 'Pancha Mahavuta'. And all we have from them is already being programmed from years together. Hence the thought which we are having now is the outcome of years and years of programming which our brain has undergone knowingly or unknowingly.

In this context we can take the 'Sankhya' philosophy (one of the six âstika (orthodox) schools of Hindu Philosophy) of 'Kapila Muni'Yoga Sutra as the base of this TPR, which has been advocated by the then intellectuals before thousands and thousands years ago. The objective is to gather knowledge on everything that exists, where it comes from and what is the end (Figure 3) [3].

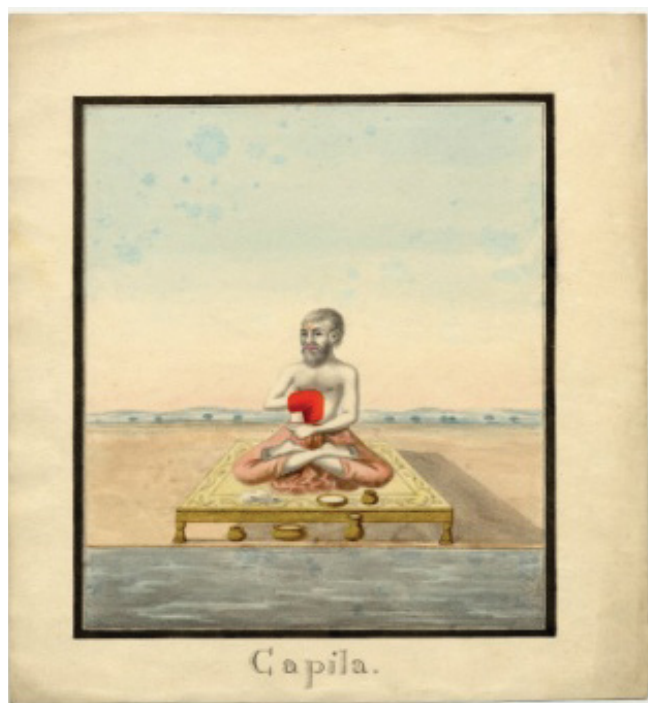

Figure 3. Sankhya philosophy.

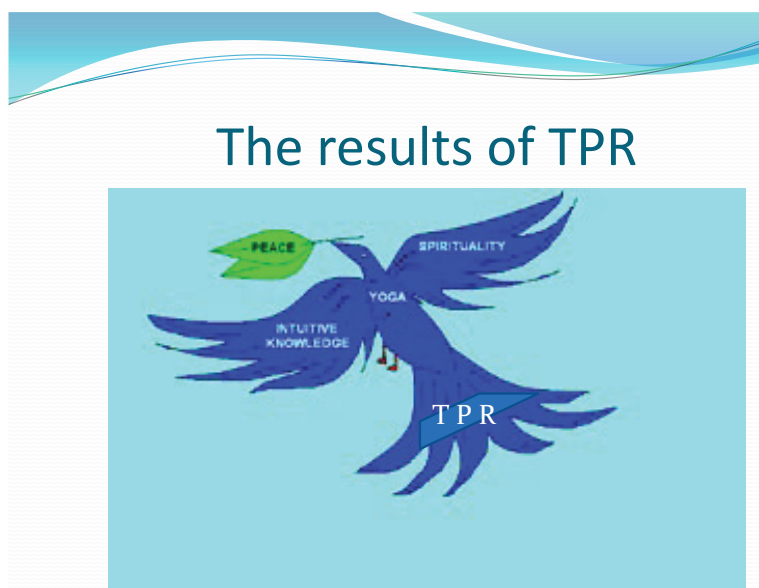

Figure 4. The results of TPR.

The Knowledge is structured based on science and spirituality. Science deals with the knowledge both relating to instinct of Eros (Life instinct) and Thanatus (Death Instincts), whereas spirituality is based on only the instinct of Eros. When they interact with Yoga, the outcome becomes tremendous. It leads to peace in body, mind and soul. The entire thought process deals with directioning the desired force in a constructive manner. The main theme is to regulate the thought in a positive way (Figure 4).

\section{Conclusion}

In a nutshell, our life is the perfect mirror of our thoughts, beliefs and dominant mental attitude. Whether we realize it or not we are already creating our reality through our thought power. Every effect we see in our outside world has its original cause within us - no exceptions. To gain access to the greatest creative power at our disposal, we must learn to control the nature of our habitual thoughts and to align our self with the One Source of All Power of which we are a part. Our thoughts create our reality. By analyzing, knowing, internalizing and applying this Truth we can transform our life in a miraculous way.

\section{References}

1. www.sajeevnair.com

2. Samkhya (2016) Internet Encyclopedia of Philosophy.

3. The Sánkhya Aphorisms of Kapila (1885) Sacred Texts.

\section{*Correspondence to:}

Santa Misra

Reader in Psychology

SSS College for Women

Bhubaneswar, Odisha

India

Tel: +91-9437211371

E-mail: santaamisraa@rediffmail.com 